\title{
非最小位相集中定数部分を含むむだ時間系に 対するループ伝達関数回復*
}

吳 景偉 $* *$. 石原 正 ${ }^{* *} \cdot$ 猪岡 光***

\author{
Loop Transfer Recovery Techniques for Time-Delay Systems \\ with Non-Minimum Phase Lumped Part*
}

Jingwei $\mathrm{WU}^{* *}$, Tadashi IshinaRA ${ }^{* * *}$ and Hikaru INOOKA***

\begin{abstract}
For a plant consisting of a lumped non-minimum phase part and an output delay, we discuss LTR(Loop Transfer Recovery) techniques for designing a predictor-based LQG controller. We focus our attention to the feedback property achieved at the plant output side. We show that a feedback property recovered by the formal application of the conventional LTR procedure can be achieved by the partial LTR technique which has a clear system-theoretic meaning. This fact provides a theoretical justification of the formal application of the conventional LTR technique to a plant including finite unstable zeros and a time delay. In addition, we point out that the partial LTR technique provides more freedom in shaping target feedback properties. We propose a simple technique exploiting this freedom. A numerical example is given to illustrate usefulness of the proposed technique.
\end{abstract}

\section{1. はじめに}

集中定数系に対しては, 非最小位相系に対するループ 伝達関数回復 (Loop Transfer Recovery: LTR) 手法 ${ }^{1}$ ) の適用に関する研究がいくつか報告されており, LTR 手 法により達成可能なフィードバック特性が明らかにされて いる2)-5)。一方，むだ時間系に対する LTR 手法の適用 に関する研究は報告されている6),7)ものの, 制御対象入 力側に対するLTR 手法に限られ, 集中定数部分が非最小 位相系である場合についての考察はされていない。しか し, このような考察は, 応用上重要なだけではなく, 最近 盛んに研究されている, むだ時間系に対する $H^{\infty}$ 制御8) との差異を明らかにするためにも必要である.

そこで, 本論文では, 非最小位相集中定数部分を含む むだ時間系に対するLTR 手法の適用について考察する. むだ時間は制御対象出力側に含まれるものとし, LTR 手

* 原稿受付 1995 年 8 月 21 日

** 東北大学 大学院 工学研究科 Faculty of Engineering, Tohoku University; Aramaki aza Aoba, Aoba-ku, Sendai city, Iwate 980-77, JAPAN

*** 東北大学 大学院 情報科学研究科 Graduate School of Information Sciences, Tohoku University; ditto

Key Words: non-minimum phase system, LQG controller, time-delay, loop transfer recovery, partial loop transfer recovery.
法は制御対象出力側に対して適用されるものとする.

本論文の構成は以下のとおりである。まず，2.で対象 とする制御系を明らかにし，制御対象出力側における感 度行列の分解表現を与える。この分解表現を用いること により，見通しの良い議論を行うことが可能となる． 3. では, 感度行列の分解表現を用い, 通常の LTR 手法を形 式的に適用して得られる感度行列の陽表現を与える。4. では部分的 LTR 手法2)の適用について考察し，この手法 により達成されるフィードバック特性はある状態予測問 題の予測誤差の挙動を記述するフィードバック系の特性 と一致することを明らかにする. 5. では, 非最小位相系 に対する二つの LTR 手法の関係について考察し, LTR 手法の形式的な適用により達成されるフィードバック特 性は部分的 LTR 手法により達成可能であることを明ら かにする.また, 部分的 LTR 手法は通常の LTR 手法に 比べ設計の自由度が大きいことを指摘する。この自由度 の利用法と数值例が 6. で与えられる.7. は結言である.

\section{2. 状態予測器に基づく LQG コントロー ラ}

制御対象はむだ時間 $\tau$ を含む次のような確率モデルで 記述されるものとする. 


$$
\begin{aligned}
& \dot{x}(t)=A x(t)+B u(t)+w(t) \\
& y(t)=C x(t-\tau)+v(t-\tau)
\end{aligned}
$$

ここで, $x(t) \in R^{n}$ は状態ベクトル,$u(t) \in R^{m}$ は制御入 力ベクトル, $y(t) \in R^{p}$ は出力ベクトルであり, $w(t)$ は外 乱べクトル,$v(t)$ は観測ノイズである. $w(t)$ および $v(t)$ は互いに独立な零平均正規性白色過程であり, その共分 散行列はそれぞれ $W \geq 0, V>0$ で与えられるものとす る.また, 行列対 $(A, B)$ と $\left(A, W^{\frac{1}{2}}\right)$ は可制御, $(C, A)$ は可観測と仮定する.さらに, $p \leq m$ であり, 伝達関数 行列 $G(s)=C(s I-A)^{-1} B$ は右可逆であり, 不安定零点 を含むものとする.

次のような 2 次形式評価関数を最小化する問題を考え る.

$$
\begin{array}{r}
J=\lim _{T \rightarrow \infty} E\left\{\frac { 1 } { T } \int _ { 0 } ^ { T } \left[y^{\prime}(t+\tau) Q y(t+\tau)\right.\right. \\
\left.\left.+u^{\prime}(t) R u(t)\right] d t\right\}
\end{array}
$$

ここで, $Q>0, R>0$ である. この評価関数を最小とす る最適フィードバック則は次のように与えられることが 知られている9).

$$
u(t)=-K_{c} \hat{x}(t \mid t-\tau)
$$

ここで， $K_{c}$ はむだ時間を考慮しない場合 $(\tau=0)$ の最適 フィードバックゲインであり, Riccati 方程式

$$
A^{\prime} P_{c}+P_{c} A-P_{c} B R^{-1} B^{\prime} P_{c}+C^{\prime} Q C=0
$$

の正定解を用いて，

$$
K_{c}=R^{-1} B^{\prime} P_{c}
$$

のように与えられる。また， $\hat{x}(t \mid t-\tau)$ は時刻 $t-\tau$ まで に得られている入出力データに基づく状態の最適予測值 であり, 次のような状態予測器により算出される.

$$
\hat{x}(t \mid t-\tau)=e^{A \tau} \hat{x}(t-\tau)+\int_{t-\tau}^{t} e^{A(t-\sigma)} B u(\sigma) d \sigma(6)
$$

ここで, $\hat{x}(t-\tau)$ は次の Kalman フィルタから求められ る $x(t-\tau)$ の最適推定值である.

$$
\begin{aligned}
\dot{\hat{x}}(t-\tau)=A \hat{x}(t-\tau) & +B u(t-\tau) \\
& +K_{f}[y(t)-C \hat{x}(t-\tau)]
\end{aligned}
$$

たたし， $K_{f}$ は Kalman フィルタゲイン行列であり, Riccati 方程式

$$
P_{f} A^{\prime}+A P_{f}-P_{f} C^{\prime} V^{-1} C P_{f}+W=0
$$

の正定解 $P_{f}$ を用いて,

$$
K_{f}=P_{f} C^{\prime} V^{-1}
$$

のように与えられる。(3) 式，(6) 式と (7) 式で与えられ るコントローラの構造を Fig. 1 に示す.このコントロー ラの伝達関数行列を $H(s)$ で表すと, $H(s)$ の左分解形は 次のように与えられることが容易に確かめられる.

$$
\begin{aligned}
H(s)= & -K_{c}\left\{I+\left[I+\left(I-e^{-(s I-A) \tau}\right)\right.\right. \\
& \left.(s I-A)^{-1} K_{f} C\right]\left(s I-A+K_{f} C\right)^{-1} \\
& \left.B K_{c}\right\}^{-1} e^{A \tau}\left(s I-A+K_{f} C\right)^{-1} K_{f}
\end{aligned}
$$

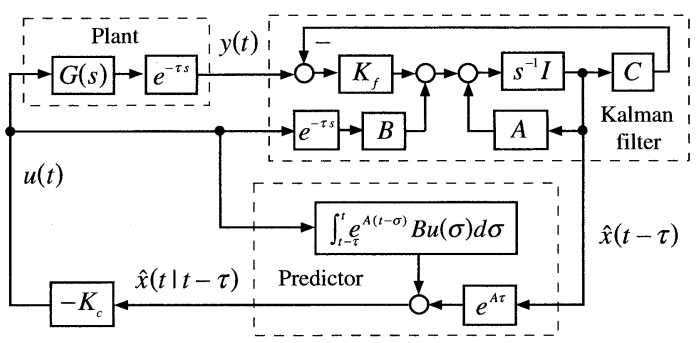

Fig. 1 Structure of the predictor-based LQG controller

若干の行列計算の後, $H(s)$ の右分解形は以下のように 与えられる。この結果は本論文で重要な役割を演ずる.

【補題 1】状態予測器 (6) 式を用いた LQG コントロ -ラ (3) 式の伝達関数行列 $H(s)$ の右分解形は次のよう に与えられる。

$$
H(s)=-K_{c}\left(s I-A+B K_{c}\right)^{-1} e^{A \cdot \tau} K_{f} F^{-1}(s)
$$

ここで

$$
\begin{aligned}
F(s)= & I+C\left[I-e^{-(s I-A) \tau}\right](s I-A)^{-1} K_{f} \\
& +C\left(s I-A+B K_{c}\right)^{-1} e^{-(s I-A) \tau} K_{f}
\end{aligned}
$$

である。

（証明）付録 参照.

上の補題を用いると，次の結果が容易に導かれる。

【補題 2】制御対象出力側における感度行列 $S(s)$ は 次のように分解できる.

$$
S(s)=F(s) S_{0}(s)
$$

ここで,

$$
S_{0}(s)=\left[I+C(s I-A)^{-1} K_{f}\right]^{-1}
$$

である。

（証明）制御対象出力側における感度行列 $S(s)$ は次の ように与えられる。 


$$
S(s)=\left[I-e^{-\tau s} C(s I-A)^{-1} B H(s)\right]^{-1}
$$

ここで，(15) 式に補題 1 を用いると，(13) 式が成立す ることが容易に確かめられる.

（注意 1）(14)式で与えられる $S_{0}(s)$ は (7) 式で与えら れる Kalmanフィルタの感度行列として知られている111).

\section{3. ループ伝達関数回復手法の形式的適用}

(1) 式で与えられる制御対象の集中定数部分の伝達関数 行列 $G(s)=C(s I-A)^{-1} B$ の次のような分解を考える.

$$
G(s)=G_{a}(s) C_{m}(s I-A)^{-1} B
$$

ここで, $C_{m}(s I-A)^{-1} B$ は最小位相伝達関数行列であ $\eta, G_{a}(s)$ は

$$
G_{a}^{\prime}(-s) G_{a}(s)=I
$$

を満足する全域通過伝達関数行列である.

このとき, 次の結果が成立することが知られている.

【補題 3】 ${ }^{3)}$ プラント (1) 式の集中定数部分の伝達関数 行列 $G(s)$ は非最小位相伝達関数行列と仮定する. 評価 関数 (2) 式の $Q$ を $q I$ とする。このとき, 最適フィード バックゲイン行列 $K_{c}$ は次の関係を満足する.

$$
\lim _{q \rightarrow \infty} q^{-\frac{1}{2}} K_{c}=R^{-\frac{1}{2}} C_{m}
$$

補題 2 と補題 3 から, 次の結果が得られる.

【命題 1】(1) 式抢よび (3) 式からなる状態予測器を用 いた LQG 制御系に抢いて, 評価関数 (2) 式の $Q$ を $q I$ とし, $q \rightarrow \infty$ とするとき, 制御対象出力側に打ける感度 行列 $S(s)$ は次の行列に漸近する.

$$
S^{*}(s)=F^{*}(s) S_{0}(s)
$$

ここで,

$$
F^{*}(s)=I+\left[C-G_{a}(s) C_{m} e^{-(s I-A) \tau}\right](s I-A)^{-1} K_{f}
$$

である。

(証明） $(s I-A)^{-1}$ を $\Phi_{A}$ ，と表す。よく知られている 逆行列補題4)を用いると,

$$
\begin{aligned}
C\left[s I-A+B K_{c}\right]^{-1}= & C\left[\Phi_{A}-\Phi_{A} B\left(q^{-\frac{1}{2}} K_{c} \Phi_{A} B\right.\right. \\
& \left.\left.+q^{-\frac{1}{2}} I\right)^{-1} q^{-\frac{1}{2}} K_{c} \Phi_{A}\right] \quad(21)
\end{aligned}
$$

が得られる. 補題 $\mathbf{3}$ と $C \Phi_{A} B\left(C_{m} \Phi_{A} B\right)^{-1}=G_{a}(s)$ で あることを用いると， $q \rightarrow \infty$ のとき, (21) 式から

$$
\lim _{q \rightarrow \infty} C\left[s I-A+B K_{c}\right]^{-1}=\left[C-G_{a}(s) C_{m}\right] \Phi_{A}
$$

が得られる. (12), (22) 式から, $\lim _{q \rightarrow \infty} F(s)=F^{*}(s)$ とな ることが判る。したがって (13) 式から (19) 式が得られ る.

$(19),(20)$ 式から明らかなように，むだ時間がなく $(\tau=$ $0), G(s)$ が最小位相系である場合には, $S^{*}(s)=S_{0}(s)$ が 成立する。したがって, 行列 $F^{*}(s)$ は LTR 手法を形式 的に適用した場合の感度行列に対する不安定零点とむた 時間の影響を表していると言える。ただし，(19), (20)式 から，そのシステム論的な意味づけを見いだすのは困難 である。

\section{4. 部分的ループ伝達関数回復}

連続時間集中定数系の制御対象入力側における部分的 LTR 手法が $\mathrm{Moor}^{2)}$ らにより提案されているが，ここで は，(1)式で与えられるむだ時間を含む系の制御対象出力 側に対する部分的 LTR 手法の適用について考察する.

\section{1 最小位相部分推定值に基づくコントローラ}

(16) 式の $G_{a}(s)$ および $G_{m}(s)$ の最小実現を, それぞ れ $\left\{A_{a}, B_{a}, C_{a}, D_{a}\right\},\left\{A, B, C_{m}\right\}$ で表す. このとき, 次 のような確率モデルを構成する.

$$
\begin{aligned}
& \dot{\chi}(t)=\Phi \chi(t)+\Gamma u(t)+\Omega w(t) \\
& y(t)=H \chi(t-\tau)+v(t-\tau)
\end{aligned}
$$

ここで,

$$
\begin{aligned}
& \Phi=\left[\begin{array}{cc}
A & 0 \\
B_{a} C_{m} & A_{a}
\end{array}\right], \quad \Gamma=\left[\begin{array}{c}
B \\
0
\end{array}\right], \\
& \Omega=\left[\begin{array}{l}
I \\
0
\end{array}\right], \quad H=\left[\begin{array}{ll}
D_{a} C_{m} & C_{a}
\end{array}\right]
\end{aligned}
$$

であり, 状態ベクトル $\chi(t)$ は全域通過部分の状態ベクト ルを $x_{a}(t)$, 最小位相部分のベクトルを $x_{m}(t)$ とすると き，次のように定義される。

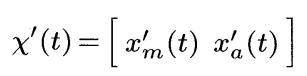

制御対象入力側の部分的 LTR は最小位相部分に加わ る仮想的外乱を利用して達成される2)が, 制御対象出力 側における部分的 LTR を達成するためには次のような 仮想的出力 $z(t)$ を定義する必要がある.

$$
z(t)=M \chi(t-\tau)=\left[\begin{array}{cc}
C_{m} & 0 \\
D_{a} C_{m} & C_{a}
\end{array}\right] \chi(t-\tau)
$$

この出力を用いて, 次のような 2 次形式評価関数を導 入する。 


$$
\begin{array}{r}
\tilde{J}=\lim _{T \rightarrow \infty} E\left\{\frac { 1 } { T } \int _ { 0 } ^ { T } \left[z^{\prime}(t+\tau) \tilde{Q} z(t+\tau)\right.\right. \\
\left.\left.+u^{\prime}(t) R u(t)\right] d t\right\}
\end{array}
$$

ここで，

$$
\tilde{Q}=\operatorname{diag}\left[\begin{array}{ll}
Q_{m} & Q_{a}
\end{array}\right], Q_{m}, Q_{a}>0, R>0
$$

である. $Q_{m}, Q_{a}$ はそれぞれ最小部分と全域通過部分に 対する出力側の重み行列である.

評価関数 (27) 式を最小とする最適フィードバック則は 次のように与えられる。

$$
u(t)=-L_{c} \hat{\chi}(t \mid t-\tau)
$$

ここで, $L_{c}$ はむだ時間を考慮しない場合 $(\tau=0)$ の最適 フィードバックゲインであり, Riccati 方程式

$$
\Phi^{\prime} \Pi_{c}+\Pi_{c} \Phi-\Pi_{c} \Gamma R^{-1} \Gamma^{\prime} \Pi_{c}+M^{\prime} \tilde{Q} M=0
$$

の非負定解 $\Pi_{c}$ を用いて次のように与えられる.

$$
L_{c}=R^{-1} \Gamma^{\prime} \Pi_{c}
$$

また, $\hat{\chi}(t \mid t-\tau)$ は状態 $\chi(t)$ の予測值であり, (23) 式に 対する Kalman フィル夕

$$
\begin{aligned}
\dot{\hat{\chi}}(t-\tau)=\Phi \hat{\chi}(t-\tau) & +\Gamma u(t-\tau) \\
& +L_{f}[y(t)-H \hat{\chi}(t-\tau)]
\end{aligned}
$$

により得られる状態推定值 $\hat{\chi}(t-\tau)$ を用いて状態予測器 により算出される。ここで，

$$
L_{f}=\Pi_{f} H^{\prime} V^{-1}
$$

は Kalman フィルタゲイン行列であり， $\Pi_{f}$ は次の Riccati 方程式の非負定解である.

$$
\Pi_{f} \Phi^{\prime}+\Phi \Pi_{f}-\Pi_{f} H^{\prime} V^{-1} H \Pi_{f}+\Omega W \Omega^{\prime}=0
$$

(29) 式のフィードバックゲイン行列の分割

$$
L_{c}=\left[\begin{array}{ll}
K_{c m} & K_{c a}
\end{array}\right]
$$

を用いると，最適フィードバック則 (29) 式は次のように 表すことができる。

$$
u(t)=-K_{c m} \hat{x}_{m}(t \mid t-\tau)-K_{c a} \hat{x}_{a}(t \mid t-\tau)
$$

ただし，

$$
\hat{\chi}^{\prime}(t \mid t-\tau)=\left[\hat{x}_{m}^{\prime}(t \mid t-\tau) \hat{x}_{a}^{\prime}(t \mid t-\tau)\right]
$$

である。このとき，制御対象入力側に対する Moore ら 2) の結果の双対として次の結果が成立する。
【補題 4】重み行列 $Q$ が次のように与えられると仮 定する。

$$
Q_{m}=q_{m} I, \quad Q_{a}=q_{a} I
$$

ここで， $q_{m}$ および $q_{a}$ は正のスカラーである.このとき， (35) 式の最適フィルタゲインは次のように与えられる.

$$
K_{c m}=R^{-1} B^{\prime} \Pi_{m m}, \quad K_{c a}=0
$$

ここで， $\Pi_{m m}$ は Riccati 方程式

$$
\begin{aligned}
A^{\prime} \Pi_{m m}+\Pi_{m m} A & -\Pi_{m m} B R^{-1} B^{\prime} \Pi_{m m} \\
& +\left(q_{m}+q_{a}\right) C_{m}^{\prime} C_{m}=0
\end{aligned}
$$

の非負定解である。

上の補題から，(36) 式で与えられる最適フィードバッ ク則は最小位相部分のみのフィードバックにより，次のよ うに実現できる。

$$
u(t)=-K_{c m} \hat{x}_{m}(t \mid t-\tau)
$$

ここで, 予測值 $\hat{x}_{m}(t \mid t-\tau)$ は, Kalman フィル夕から求 められる $x_{m}(t-\tau)$ の推定值 $\hat{x}_{m}(t-\tau)$ を用いて, 次の ような状態予測器により算出される。

$$
\hat{x}_{m}(t \mid t-\tau)=e^{A \tau} \hat{x}_{m}(t-\tau)+\int_{t-\tau}^{t} e^{A(t-\sigma)} B u(\sigma) d \sigma
$$

(33) 式の Kalman フィルタゲイン行列 $L_{f}$ を次のように 分割する.

$$
L_{f}^{\prime}=\left[\begin{array}{ll}
K_{f m}^{\prime} & K_{f a}^{\prime}
\end{array}\right]
$$

(32) 式を最小位相部分と全域通過部分に分解して表すと, 次のようになる。

$$
\begin{aligned}
\dot{\hat{x}}_{m}(t-\tau)= & A \hat{x}_{m}(t-\tau)+B u(t-\tau)+K_{f m}[y(t) \\
& \left.-D_{a} C_{m} \hat{x}_{m}(t-\tau)-C_{a} \hat{x}_{a}(t-\tau)\right](44) \\
\dot{\hat{x}}_{a}(t-\tau)= & A_{a} \hat{x}_{a}(t-\tau)+B_{a} C_{m} \hat{x}_{m}(t-\tau) \\
& +K_{f a}\left[y(t)-D_{a} C_{m} \hat{x}_{m}(t-\tau)\right. \\
& \left.-C_{a} \hat{x}_{a}(t-\tau)\right]
\end{aligned}
$$

(45) 式を (44) 式に用いると, 次のような最小位相部分の みを推定する Kalman フィルタを構成できる。

$$
\begin{aligned}
\hat{x}_{m}(s)= & {\left[s I-A+M(s) G_{a}(s) C_{m}\right]^{-1} } \\
& \left\{B u(s)+e^{\tau s} M(s) y(s)\right\}
\end{aligned}
$$

ここで, フィルタゲイン行列 $M(s)$ は次のように与えら れる。 


$$
M(s)=K_{f m}\left[I+C_{a}\left(s I-A_{a}\right)^{-1} K_{f a}\right]^{-1}
$$

また，

$$
\hat{x}_{m}(s)=\mathcal{L}\left\{\hat{x}_{m}(t)\right\}
$$

であり, $u(s), y(s)$ はそれぞれ $u(t), y(t)$ のラプラス変 換である。

(41) 式で与えられるコントローラを, 以下, 最小位相 部分状態フィードバック (Minimum-phase Estimator Feedback, MEF) コントローラと呼ぶことにする.

\section{2 感度行列の分解表現と部分的 LTR}

$\mathrm{MEF}$ コントローラは Fig. 1 のコントローラの出力行列 $C$ およびフィルタゲイン行列 $K_{f}$ をそれぞれ $G_{a}(s) C_{m}$, $M(s)$ と動的なものに置き換えた構造であることがわか る.

この関係を 補題 $\mathbf{2}$ に用いると, 次の結果が直ちに得ら れる。

【補題 5】 MEF コントローラを用いた場合, 制御対象 出力側における感度行列 $\Sigma(s)$ は次のように与えられる.

$$
\Sigma(s)=\Psi(s) \Sigma_{0}(s)
$$

ここで,

$$
\begin{aligned}
\Psi(s)= & I+G_{a}(s) C_{m}\left[I-e^{-(s I-A) \tau}\right] \\
& (s l-A)^{-1} M(s)+G_{a}(s) C_{m} \\
& \left(s l-A+B K_{c m}\right)^{-1} e^{-(s I-A) \tau} M(s) \\
\Sigma_{0}(s)= & {\left[I+G_{a}(s) C_{m}(s I-A)^{-1} M(s)\right]^{-1} }
\end{aligned}
$$

である。

Riccati 方程式 (40) 式と (4) 式で $Q=q_{m} I$ とした Riccati 方程式の関係に着目すると, 補題 $\mathbf{3}$ と (39) 式から

$$
\lim _{q_{m} \rightarrow \infty} q_{m}^{-\frac{1}{2}} K_{c m}=R^{-\frac{1}{2}} C_{m}
$$

が成立することが判る。この結果と前述の対応関係を用い ると, 命題 1 の証明と同様に次の結果が容易に得られる.

【命題 2】 MEF コントローラを用いた場合, $q_{m} \rightarrow \infty$ とすると, (49) 式で与えられる感度行列 $\Sigma(s)$ は次の行 列に漸近する。

$$
\Sigma^{*}(s)=\Psi^{*}(s) \Sigma_{0}(s)
$$

ここで,

$$
\begin{aligned}
\Psi^{*}(s)= & I+G_{a}(s) C_{m} \\
& {\left[I-e^{-(s I-A) \tau}\right](s I-A)^{-1} M(s) }
\end{aligned}
$$

である。
4.3 最小位相部分予測誤差フィードバック系 ここでは, 命題 2 で与えられる感度行列の漸近值は最 小位相部分の予測誤差を与えるフィードバック系の感度 行列に一致することを示す。この事実は，むだ時間系の 制御対象出力側に対する部分的 LTR 手法のシステム論 的な意義を明らかにするものである．なお，以下の議論 では, 表現を簡単にするために, 時間 $t$ とラプラス演算 子 $s$ が混在した表現を用いることがあるが， $s$ を微分演 算子とみなせば問題は生じない。

(23) 式で, $u(t)=0$ とした状態予測問題を考える.こ のとき，(46) 式は次のような最小位相部分のみに関係す るKalmanフィルタになる。

$$
\begin{aligned}
\dot{\hat{x}}_{m}(t-\tau)= & A \hat{x}_{m}(t-\tau)+M(s) \\
& {\left[y(t)-G_{a}(s) C_{m} \hat{x}_{m}(t-\tau)\right] }
\end{aligned}
$$

最小位相部分の状態予測值 $\hat{x}_{m}(t \mid t-\tau)$ は (42) 式で $u(t)=$ 0 とおくことにより, 次の状態予測器により算出される.

$$
\hat{x}_{m}(t \mid t-\tau)=e^{A \tau} \hat{x}_{m}(t-\tau)
$$

出力の最適予測値 $\hat{y}(t \mid t-\tau)$ は (56) 式を用いて次のよう に与えられる。

$$
\hat{y}(t \mid t-\tau)=G_{a}(s) C_{m} e^{-\tau s} \hat{x}_{m}(t \mid t-\tau)
$$

(56) 式および (57) 式を用いると，(55) 式は次のよう に書き換えられる。

$$
\begin{aligned}
s \hat{x}_{m}(s)= & A \hat{x}_{m}(s)+M(s)\left\{e^{\tau s}\left[y(s)-\hat{y}_{\tau}(s)\right]\right. \\
& \left.-G_{a}(s) C_{m}\left(I-e^{-(s I-A) \tau}\right) \hat{x}_{m}(s)\right\}
\end{aligned}
$$

ここで,

$$
\hat{y}_{\tau}(s)=\mathcal{L}\{\hat{y}(t \mid t-\tau)\}
$$

である.(58) 式はさらに次のように書き換えられる.

$$
\hat{x}_{m}(s)=(s I-A)^{-1} M(s)\left[\Psi^{*}(s)\right]^{-1}\left[y(s)-\hat{y}_{\tau}(s)\right](60)
$$

ここで，最小位相部分の状態予測值のラプラス変換を

$$
\hat{x}_{m, \tau}(s)=\mathcal{L}\left\{\hat{x}_{m}(t \mid t-\tau)\right\}
$$

とすると, (56) 式から

$$
\begin{aligned}
& \hat{x}_{m, \tau}(s)= \\
& \quad\left[s I-A+e^{-\tau s} \tilde{M}(s) G_{a}(s) C_{m}\right]^{-1} \tilde{M}(s) y(s)(62)
\end{aligned}
$$

が得られる。ここで，

$$
\tilde{M}(s)=e^{A \tau} M(s)\left[\Psi^{*}(s)\right]^{-1}
$$


である。

外乱 $w(t)$ と観測ノイズ $v(t)$ は存在しないとすると, 最小位相部分の挙動は $\dot{x}_{m}(t)=A x_{m}(t)$ で表され，また， 出力の予測誤差は $y(s)-\hat{y}_{\tau}(s)=e^{-\tau s} G_{a}(s) C_{m} \tilde{x}_{m, \tau}(s)$ と表される。したがって, (62) 式から, 最小位相部分の 状態予測誤差

$$
\tilde{x}_{m, \tau}(s)=x_{m}(s)-\hat{x}_{m, \tau}(s)
$$

の挙動は次のように与えられる.

$$
s \tilde{x}_{m, \tau}(s)=A \tilde{x}_{m, \tau}(s)-e^{-\tau s} \tilde{M}(s) G_{a}(s) C_{m} \tilde{x}_{m, \tau}(s)
$$

上式右辺の第 2 項は開ループ予測誤差系 $s \tilde{x}_{m, \tau}(s)=$ $A \tilde{x}_{m, \tau}(s)$ に対するフィードバックと見なせる. 以下, こ の系を最小位相部分状態予測誤差フィードバック (Minimum-phase Prediction-error Feedback, MPF) システ ムと呼ぶことにする。この系の構造を Fig. 2 に示す.

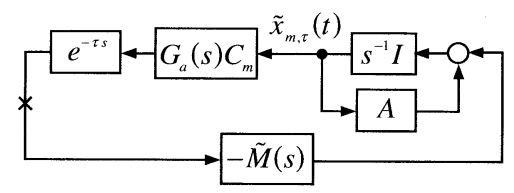

Fig. 2 Structure of the MPF system

【補題 6】Fig. 2 に示される MPF システムにおい て, 図の×印の位置に拈ける感度行列は次のように与え られる。

$$
\Sigma^{M P F}(s)=\Psi^{*}(s) \Sigma_{0}(s)
$$

(証明) MPF システムの予測誤差出力感度行列は次の ように与えられる。

$$
\Sigma^{M P F}(s)=\left[I+e^{-\tau s} G_{a}(s) C_{m}(s I-A)^{-1} \tilde{M}(s)\right]^{-1}
$$

(54), (63) 式を用いると, (67) 式から (66) 式が得られる.

命題 2 と上の補題から次の結果がただちに得られる.

【命題 3】 MEF コントローラを用いた部分的 LTR 手 法により, 制御対象出力側において達成されるフィード バック特性は, MPF システムの出力側において達成され るフィードバック特性と一致する.

\section{5. 二つの LTR 手法の関係}

最近, 石原 ${ }^{5)}$ は集中定数離散時間系に対して, 通常の ループ伝達関数回復の手続きの形式的適用により達成さ れるフィードバック特性は部分的ループ伝達関数回復手 法により達成可能であることを明らかにしている. 5. で は, 同様のことが, 非最小位相集中定数部分を含むむだ 時間系に対しても成立することを示す.

以下の議論では, (16)式の分解をより具体的に求める

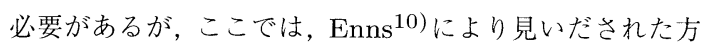
法を用いる。簡単のために, $C(s I-A)^{-1} B$ は不安定零 点は 1 個の実零点であるものとする.

【補題 7】 10) 伝達関数行列 $G(s)=C(s I-A)^{-1} B$ は 1 個の不安定な零点 $z(z>0)$ を含むものと仮定する. 不 安定零点 $z$ に対応する零方向単位ベクトルおよび零状態 ベクトルをそれぞれ $\eta, \xi$ とする.すなわち,

$$
\left[\begin{array}{ll}
\xi^{\prime} & \eta^{\prime}
\end{array}\right]\left[\begin{array}{cc}
z I-A & -B \\
-C & 0
\end{array}\right]=0, \quad \eta^{\prime} \eta=1
$$

が成立しているものとする。このとき, $G(s)$ の分解 $(16)$ 式の $G_{a}(s)$ と $C_{m}$ は次のように与えられる.

$$
G_{a}(s)=I-\frac{2 z}{s+z} \eta \eta^{\prime}
$$

$$
C_{m}=C-2 z \eta \xi^{\prime}
$$

ここで, $G_{a}(s)=\left\{A_{a}, B_{a}, C_{a}, D_{a}\right\}$ とすれば,

$$
A_{a}=-z, B_{a}=\eta^{\prime}, C_{a}=-2 z \eta, D_{a}=I
$$

である、

上の補題は $G(s)$ から 1 個の不安定零点を取り出し, 全 域通過要素を構成する手続きを与えていることに注意し よう. $G(s)$ が複数個の不安定零点を含む場合には, 上の 補題の手続きを繰り返すことにより，(16) 式の分解が得 られる10).

上の補題を用いると, 以下の四つの補題が容易に導か れる.

【補題 8】プラント (1) 式の集中定数部分伝達関数行 列 $G(s)=C(s I-A)^{-1} B$ は 1 個の不安定零点 $z(z>0)$ を含むものと仮定する．次のような行列を定義する.

$$
N=\left[\begin{array}{ll}
I & -\xi
\end{array}\right]^{\prime}
$$

このとき, 次の関係が成立する.

$$
\Phi N=N A, N B=\Gamma, H N=C
$$

(証明略) 
【補題 9】(1) 式の外乱 $w(t)$ の共分散行列が $W=$ $B B^{\prime}$ で与えられるとすると, Riccati 方程式 (8) 式の解 $P_{f}$ と (34) 式の解 $\Pi_{f}$ の間には次の関係が成立する.

$$
\Pi_{f}=N P_{f} N^{\prime}
$$

（証明）(34) 式の左辺を $R i c\left(\Pi_{f}\right)$ と表す. $P_{f}$ はRiccati 方程式 (8) 式を満足しているものとする．このとき, $\Omega B=N B, W=B B^{\prime}$ が成立していることと補題 8 を 用いると

$$
\begin{aligned}
\operatorname{Ric}\left(\Pi_{f}\right)= & N P_{f} N^{\prime} \Phi^{\prime}+\Phi N P_{f} N^{\prime} \\
& -N P_{f} N^{\prime} H^{\prime} V^{-1} H N P_{f} N^{\prime}+N B B^{\prime} N^{\prime} \\
= & N\left\{P_{f} A^{\prime}+A P_{f}\right. \\
& \left.-P_{f} C^{\prime} V^{-1} C P_{f}+B B^{\prime}\right\} N^{\prime} \\
= & 0
\end{aligned}
$$

が得られる.すなわち, (74) 式で与えられる $\Pi_{f}$ は Riccati 方程式 (8)の唯一非負定解である.

【補題 10】補題 9 の仮定は成立しているものとする. このとき, 確率モデル (23) 式に対する Kalman フィルタ (32) のゲイン行列 $L_{f}$ の分割 (43) 式に対して次の関係が 成立する。

$$
K_{f m}=K_{f}, \quad K_{f a}=-\xi^{\prime} K_{f}
$$

ここで, $K_{f}$ は $(9)$ 式で定義される Kalman フィルタゲ イン行列である. (証明略)

【補題 11】補題 9 の仮定が成立しているものとする. このとき，次の関係が成立する。

$$
\begin{aligned}
& C_{a}\left(s I-A_{a}\right)^{-1} K_{f a}+G_{a}(s) C_{m}(s I-A)^{-1} K_{f m} \\
& \quad=C(s I-A)^{-1} K_{f}
\end{aligned}
$$

(証明略)

【命題 4】プラント (1) 式の伝達関数行列 $G(s)=$ $C(s I-A)^{-1} B$ は 1 個の不安定零点 $z(z>0)$ を含むも のと仮定する. また，(1) 式の外乱 $w(t)$ の共分散行列が $W=B B^{\prime}$ で与えられるとする。このとき，(19) 式で定 義される感度行列 $S^{*}(s)$ と $(66)$ 式で与えられる感度行列 $\Sigma^{*}(s)$ は一致する.

（証明）(47) 式と (76) 式を用いると，(53) 式は次のよ うに表される。

$$
\begin{aligned}
\Sigma^{*}(s)= & \left\{I+C_{a}\left(s I-A_{a}\right)^{-1} K_{f a}+G_{a}(s) C_{m}\right. \\
& {\left.\left[I-e^{-(s I-A) \tau}\right](s I-A)^{-1} K_{f m}\right\} } \\
& {\left[I+C_{a}\left(s I-A_{a}\right)^{-1} K_{f a}\right.} \\
& \left.+G_{a}(s) C_{m}(s I-A)^{-1} K_{f m}\right]^{-1}
\end{aligned}
$$

補題 11 を用いると, 上式は次のように書き換えられる。

$$
\begin{aligned}
\Sigma^{*}(s)= & \left\{I-G_{a}(s) C_{m}(s I-A)^{-1} e^{-(s I-A) \tau} K_{f}\right. \\
& \left.+C(s I-A)^{-1} K_{f}\right\} \\
& {\left[I+C(s I-A)^{-1} K_{f}\right]^{-1} }
\end{aligned}
$$

ここで，上式と $(19),(20)$ 式とを比較すると $S^{*}(s)=$ $\Sigma^{*}(s)$ であることがわかる.

上の結果は，通常の LTR 手法を形式的に適用して得 られるフィードバック特性は部分的 LTR 手法により達成 可能であることを示している. 部分的 LTR 手法は非最小 位相部分に関連するフィードバック特性のみを回復しよ うとする明確な意図に基づいている。したがって，上の結 果は非最小位相系に対するLTR 手法の形式的適用に対し て明確なシステム論的意味付けを与えると言える。また， 上の結果は, 部分的 LTR 手法により達成されるフィード バック特性を回復するためには, MEF コントローラを用 いる必要はなく, 2. で与えた状態予測器を含む LQGコ ントローラを用いれば十分であることも示している。し かし, このことは, 上の命題で与えた確率モデルに対し て言えることである. 部分的 LTR 手法では, より一般的 な確率モデルを用いることが可能であり, その場合通常 の LTR 手法では回復できないフィードバック特性を実現 することが可能である.

なお, 上の命題は制御対象が複数個の不安定零点を持 つ場合に対して容易に一般化される.

\section{6. 部分的 LTR の自由度の利用と数值例}

6. では, 部分的 LTR 手法の自由度を利用する一方法 を提案し，その有効性を数值例を通して検討する。

\section{1 周波数依存共分散行列}

(23) 式よりも一般的な次のような確率モデルを考える.

$$
\begin{aligned}
& \dot{\chi}(t)=\Phi \chi(t)+\Gamma u(t)+\omega(t) \\
& y(t)=H \chi(t-\tau)+v(t-\tau)
\end{aligned}
$$

ここで,

$$
\omega(t)=\left[\omega_{m}^{\prime}(t) \omega_{a}^{\prime}(t)\right]^{\prime}
$$

$\omega(t)$ は新たに導入された零平均正規性白色過程であり, その共分散行列は

$$
\tilde{\Omega}=\text { block diag }\left[\begin{array}{ll}
\Omega_{m} & \Omega_{a}
\end{array}\right]
$$

で与えられるものとする. $\Omega_{m}=W, \Omega_{a}=0$ とすると， (80) 式は (23) 式と一致する。(24) 式を用いると，(80) 式 は次のように書き換えられる. 


$$
\begin{aligned}
\dot{x}_{m}(t) & =A x(t)+B u(t)+\omega_{m}(t) \\
y(t)= & G_{a}(s) C_{m} x_{m}(t-\tau)+C_{a}(s I-A)^{-1} \omega_{a}(t-\tau) \\
& +v(t-\tau)
\end{aligned}
$$

上式の観測方程式と統計的に等価な次のような観測系を 考えることができる。

$$
y(t)=G_{a}(s) C_{m} x_{m}(t-\tau)+V_{a}(s) \varepsilon(t-\tau)
$$

ここで, $\varepsilon(t)$ は単位共分散行列の零平均正規性白色過程 であり, $V_{a}(s)$ は次の関係を満足する行列である.

$$
\begin{aligned}
V_{a}(s) V_{a}^{\prime}(-s)= & V+C_{a}\left(s I-A_{a}\right)^{-1} \Omega_{a} \\
& \left(-s I-A_{a}^{\prime}\right)^{-1} C_{a}^{\prime}
\end{aligned}
$$

上式はスペクトル分解の関係であり, $V_{a}(s)$ は Riccati 方 程式

$$
P_{a} A_{a}^{\prime}+A_{a} P_{a}-P_{a} C_{a}^{\prime} V^{-1} C_{a} P_{a}+\Omega_{a}=0
$$

の非負定解 $P_{a}$ を用いて次のように与えられる11).

$$
V_{a}(s)=\left[I+C_{a}\left(s I-A_{a}\right)^{-1} P_{a} C_{a}^{\prime} V^{-1}\right]^{\frac{1}{2}}
$$

ここで, $A_{a}$ は安定で, $\left(C_{a}, A_{a}\right)$ は可観測なので, 任意 の $\Omega_{a} \geq 0$ に対して，(86) 式の非負定解 $P_{a}$ が存在する. したがって，(85) 式を満足する安定な $V_{a}(s)$ の存在が保 証される.

さて，(85) 式は，(84) 式で与えられる観測系の観測ノ イズが周波数依存の共分散行列 $V_{a}(s) V^{\prime}(s)$ を持つ（成形 フィルタ $V_{a}(s)$ で表される) 有色過程であることを示し ている。この（仮想的な）観測ノイズの周波数特性は共 分散行列 $\Omega_{a}$ により決定される。したがって， $\Omega_{a}$ を所望 のフィードバック特性が得られるように調整することに より，通常の LTR 手法では達成できないフィードバック 特性を実現できる。

（注意 2）LTR 手法は，制御対象が最小位相系であれ ば，周波数依存の重み係数行列や共分散行列に対しても 適用可能であることはすでに指摘されている1)。6. で提 案した方法はむだ時間を含む非最小位相系に対して，目 標特性を調整するために有効な周波数依存の共分散行列 の具体的な構成法を与えていることに注意されたい.

\section{2 数值例}

次のような 1 入力 1 出力系を考える.

$$
P(s)=\frac{2(s-4)}{s\left(s^{2}+3 s+2\right)} e^{-2 s}
$$

この系の集中定数部分は不安定な零点 $s=4$ を含む非最 小位相系であり, $G_{m}(s)$ と $G_{a}(s)$ の状態空間表現はそ れぞれ次のように与えられる。

$$
\begin{aligned}
& A=\left[\begin{array}{rrr}
0 & 1 & 0 \\
0 & 0 & 1 \\
0 & -2 & -3
\end{array}\right], \quad B=\left[\begin{array}{l}
0 \\
0 \\
1
\end{array}\right], \\
& C_{m}=\left[\begin{array}{lll}
8 & 2 & 0
\end{array}\right] \\
& A_{a}=-4, B_{a}=1, C_{a}=-8, D_{a}=1
\end{aligned}
$$

(80) 式の確率モデルに対して, $\omega(t)$ の共分散行列を次の ように選ぶ.

$$
\Omega_{a}=\mu V, \quad \Omega_{m}=B B^{\prime}
$$

ここで， $\mu$ は正のスカラーであり， $V$ は観測ノイズ $v(t)$ の共分散行列である.さらに, 成形フィル夕の伝達関数 $V_{a}(s)$ を次のように選ぶ.

$$
V_{a}(s)=V^{\frac{1}{2}} \psi_{a}(s)
$$

ここで, $\psi_{a}(s)$ は次のスペクトル分解により定義される。

$$
\psi_{a}(s) \psi_{a}(-s)=1+\frac{\mu}{\left(s-A_{a}\right)\left(-s-A_{a}\right)}
$$

さらに, $\sigma$ は正実数とし, 共分散行列 $V$ を

$$
V=\frac{\sigma^{2}}{\psi_{a}^{2}(0)}
$$

と選ぶ.すなわち, $V_{a}(0)=\sigma$ が成立する.このように $\sigma$, $\mu$ を選ぶと, $V_{a}(s)$ の直流ゲインと高域での特性を, そ れぞれ， $\sigma, \mu$ により独立に調整できる.

$\sigma^{2}=0.1$ とした場合の目標特性の感度関数と相補感度 関数のゲイン特性をそれぞれ Fig. 3 および Fig. 4 に示 す。パラメータ $\mu$ により，低域の特性を大きく変えずに， 高域での特性を調整できるのがわかる．とくに， $\mu$ を増 加させることにより, 相補感度の高域におけるゲインを 低下させることができる点は，モデル化誤差に対するロ

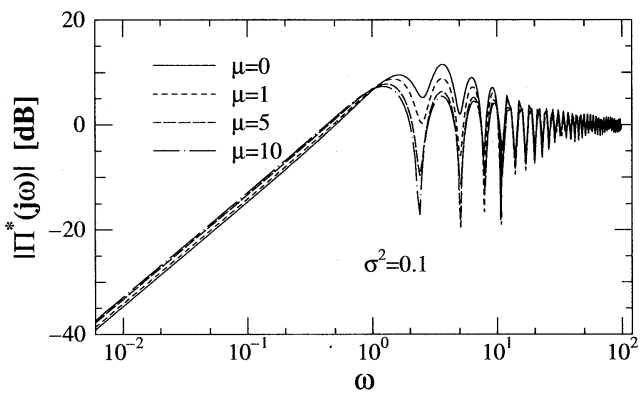

Fig. 3 Effect of the parameter $\mu$ on the target sensitivity function 


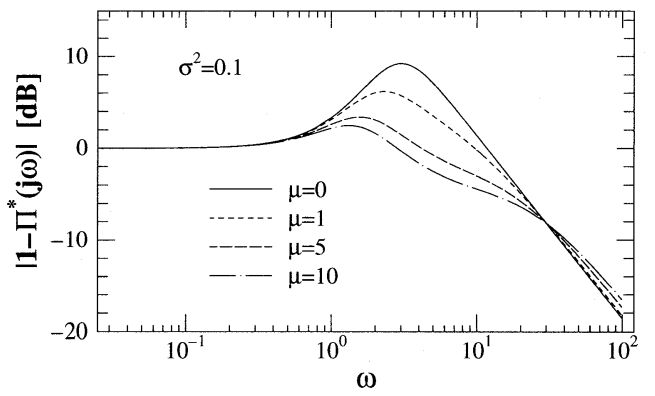

Fig. 4 Effect of the parameter $\mu$ on the target complementary sensitivity function

バスト性を改善するために有用である.

\section{7. おわりに}

非最小位相集中定数部分を含むむだ時間系に対する LTR 手法の適用について考察した．通常の手法を形式的 に適用して得られるフィードバック特性は, 部分的 LTR 手法により達成されるものと一致することを示した。ま た，このフィードバック特性は，ある状態予測問題の誤差 フィードバック系の特性と解釈できることを明らかにし た。これらの結果は, 非最小位相系に対する LTR 手法の システム論的な意義を明らかにするものである。さらに， 部分的 LTR 手法の自由度の利用法を提案し, その有効 性を数值例により確認した。なお，制御対象入力側に対 しては, 本論文に双対な結果が成立し, そのシステム論 的な意味付けは容易である。

\section{参考文献}

1) G. Stein and M. Athans: The LQG/LTR procedure for multivariable feedback control design; IEEE Trans. Automat. Contr., Vol. 32, No. 2, pp. 105-114 (1987)

2) J. B. Moore and L. Xia: Loop recovery and robust state estimate feedback designs; IEEE Trans. Automat. Contr., Vol. 32, No. 6, pp. 512-517 (1987)

3) Z. Zhang and J. S. Freudenberg: Loop transfer recovery for non-minimum phase plants; IEEE Trans. Automat. Contr., Vol. 35, No. 5, pp. 547-553 (1990)

4) J. M. Maciejowski: Asymptotic recovery for discretetime systems; IEEE Trans. Automat. Contr., Vol. 30, No. 6, pp. 602-605 (1985)

5) 石原:離散時間非最小位相系に対するループ伝達関数回復につ いて; 計測自動制御学会論文集, Vol. 30 , No. 10, pp. 11721177 (1994)

6) W. H. Kwon and S. J. Lee: LQG/LTR methods for linear systems with delay in state; IEEE Trans. Automat. Contr., Vol. 33, No. 7, pp. 681-687 (1988)

7) S. J. Lee, W. H. Kwon and S. W. Kim: LQG/LTR methods for linear input-delayed systems; Int. J. Control, Vol. 47, No. 5, pp. 1179-1194 (1988)
8) 児島:むだ時間系の $H^{\infty}$ 制御;システム/制御/情報, Vol. 39, No. 2, pp. 74-80 (1988)

9) D. L. Kleinman: Optimal control of linear system with time-delay and observation noise; IEEE Trans. Automat. Contr., Vol. 14, No. 10, pp. 524-526 (1969)

10) D. Enns: Model Reduction for Control System Design, Ph. D. dissertation, Stanford Univ. (1984)

11) B. D. O. Anderson and J. B. Moore: Optimal Control: Linear Quadratic Methods, Prentice-Hall (1990)

12) J. M. Maciejowski: Multivariable Feedback Design, Addison-Wesley Publishing Company (1989)

\section{付 録}

\section{補題 1 の証明}

まず，次のような行列を定義する.

$$
\begin{aligned}
& W(s)=I+\left[I-e^{-(s I-A) \tau}\right](s I-A)^{-1} K_{f} C \\
& \tilde{W}(s)=I+K_{f} C\left[I-e^{-(s I-A) \tau}\right](s I-A)^{-1} \\
& F_{f}(s)=I+C\left[I-e^{-(s I-A) \tau}\right](s I-A)^{-1} K_{f}
\end{aligned}
$$

(A1) 式, (A2) 式と (A3) 式から, 明らかに

$$
\begin{aligned}
& \tilde{W}^{-1}(s) K_{f} C=K_{f} C W^{-1}(s) . \\
& C W^{-1}(s)=F_{f}^{-1}(s) C \\
& \tilde{W}^{-1}(s) K_{f}=K_{f} F_{f}^{-1}(s)
\end{aligned}
$$

が成立する. (A1) 式の両辺に左から $(s I-A)$ をかけて, 右から $W^{-1}(s)$ をかけると，

$$
\begin{aligned}
(s I & \left.-A+K_{f} C\right) W^{-1}(s) \\
& =(s I-A)+e^{-(s I-A) \tau} K_{f} C W^{-1}(s)
\end{aligned}
$$

が得られる。同様に

$$
\begin{aligned}
& \tilde{W}^{-1}(s)\left(s I-A+K_{f} C\right) \\
& \quad=(s I-A)+\tilde{W}^{-1}(s) K_{f} C e^{-(s I-A) \tau}
\end{aligned}
$$

が得られる。

(A7) 式に左から $e^{(s I-A) \tau}$ をかけて, (A8) 式に右から $e^{(s I-A) \tau}$ をかけると,

$$
\begin{aligned}
& e^{(s I-A) \tau}\left(s I-A+K_{f} C\right) W^{-1}(s) \\
& \quad=e^{(s I-A) \tau}(s I-A)+K_{f} C W^{-1}(s) \\
& \tilde{W}^{-1}(s)\left(s I-A+K_{f} C\right) e^{(s I-A) \tau} \\
& \quad=(s I-A) e^{(s I-A) \tau}+\tilde{W}^{-1}(s) K_{f} C
\end{aligned}
$$

が得られる。(A4) 式を (A9) 式と (A10) 式に用いると, 


$$
\begin{aligned}
& W^{-1}(s) e^{A \tau}\left(s I-A+K_{f} C\right)^{-1} \\
& \quad=\left(s I-A+K_{f} C\right)^{-1} e^{A \tau} \tilde{W}^{-1}(s)
\end{aligned}
$$

が得られる．以上の準備のもとで，(11)式が以下のよう

に得られる。(A1) 式を (10) 式に代入すると,

$$
\begin{gathered}
H(s)=-K_{c}\left[I+W(s)\left(s I-A+K_{f} C\right)^{-1} B K_{c}\right]^{-1} \\
e^{A \tau}\left(s I-A+K_{f} C\right)^{-1} K_{f}
\end{gathered}
$$

が得られる。ここで, (A7) 式と (A11) 式を用いると， (A12) 式は次のように書き換えられる.

$$
\begin{aligned}
H(s)= & -K_{c}\left[\left(s I-A+B K_{c}\right)+e^{-(s I-A) \tau} K_{f} C\right. \\
& \left.W^{-1}(s)\right]^{-1} e^{A \tau} \tilde{W}^{-1}(s) K_{f}
\end{aligned}
$$

さらに（A5) 式と (A6) 式を (A13) 式に代入すると,

$$
\begin{aligned}
H(s)= & -K_{c}\left[\left(s I-A+B K_{c}\right)+e^{-(s I-A) \tau}\right. \\
& \left.K_{f} F_{f}^{-1}(s) C\right]^{-1} e^{A \tau} K_{f} F_{f}^{-1}(s) \\
= & -K_{c}\left(s I-A+B K_{c}\right)^{-1} e^{A \tau} K_{f}\left[F_{f}(s)\right. \\
& \left.+C\left(s I-A+B K_{c}\right)^{-1} e^{-(s I-A) \tau} K_{f}\right]^{-1}
\end{aligned}
$$

が得られる。(A3) 式に注意すると，(11) 式が成立するこ とがわかる。 